\title{
Implementation of Vague-Fuzzification using Vague Sets
}

\author{
Priya Hooda \\ ITM University \\ Dept. of Computer Science and Engineering \\ Gurgaon, India
}

\author{
Supriya Raheja \\ ITM University \\ Dept. of Computer Science and Engineering \\ Gurgaon, India
}

\begin{abstract}
A mathematical procedure used to convert an element in the universe of discourse into the membership value of the fuzzy set is termed as fuzzification. In this paper we propose a new technique Vague-Fuzzification to implement fuzzification using vague sets. The proposed technique is designed that is using two methods to implement the same. First method includes a positive ordered transforming formula (POTF) that transforms a non-negative single value data to vague data. The second method takes as input the output of first method and converts the vague data to fuzzified membership values. The technique is implemented using MATLAB and the results of two different data sets are summarized in the form of tables.
\end{abstract}

\section{Keywords}

Fuzzification; Fuzzy Sets; Vague Sets; Membership Functions

\section{INTRODUCTION}

In the real physical world, the sets of elements do not have precisely defined criteria of membership [1]. We use the concept of Fuzzy Sets and Membership Functions that permits the gradual assessment of membership of an element to a particular set. A fuzzy set extends the binary membership: $\{0$, 1 ) of a conventional set to a spectrum in the interval of $[0,1]$ [2]. It is a way to deal with uncertainty by attaching degrees of certainty. Our day-to-day situations which includes "probably yes", "maybe", "not sure", "that depends" are easily implemented with the Fuzzy Sets and Fuzzy Logic concepts.

In fuzzy set theory, fuzzification technique assigns the degree of membership to an element in a set. The different types of membership functions are Triangular Membership Function, Trapezoidal Membership Function, and Gaussian Membership Function etc. These are the traditional techniques to map an input value to output space.

But, there are situations when elements stand in an abstained or neutrality condition. For ex, suppose in a set of 10 elements, 5 elements are in favour of a decision, 3 are against the decision and 2 elements are not able to choose the side. Here, these 2 elements stand in neutrality condition. For these kinds of conditions we use Vague Sets and Vague Logic, which removes the abstained condition and provides the exact belongingness. A Vague Set $\mathrm{V}(\mathrm{X})$ in $\mathrm{X}$ is characterized by a truth-membership function $t_{v}$, and $a$ false-membership function $f_{v}$, where $t_{v}+f_{v}<=1[3]$.

In this research paper, we are introducing a new technique to map a single valued data to a fuzzy value using vague sets.

This research paper is organized into 7 sections. Section 2 describes related work. A brief discussion on fuzzy sets and vague sets is in section 3. Section 4 includes fuzzification techniques. Proposed technique Vague-Fuzzification is explained in section 5. Section 6 contains result and a comparison of two methods. In the last, section 7 comprises of conclusion.

\section{RELATED WORK}

Amit Kumar [4] discussed and proposed an algorithm that performs different arithmetic operations between different types of vague sets in his research paper Fuzzy System Reliability Using Different Types of Vague Sets. Using the algorithm methods to analyze fuzzy reliability of various systems are obtained. He discussed about fuzzy reliability of systems in which components have different types of membership functions. The fuzzy reliability of components of the systems are represented by different types of vague sets.

Kevin M. Passino [5], in his book Fuzzy Control discussed two types of membership functions, namely triangular and trapezoidal shapes along with expressions. According to him the function associated with a specific linguistic value that maps a universe of discourse to $[0,1]$ is called a membership function. In his book, it is also emphasised that different shapes of membership functions are possible and each will provide a different fuzzyfied value.

Li Guxin [6] studied transforming formulas that converts single value raw data into vague data, i.e. in truth and false membership function values. Subjected to different conditions two types of transforming formulas are provided namely, Positive Ordered transforming Formula (POTF) and Reverse Ordered Transforming Formula (ROTF). This research paper provides one of the key steps to create a vague environment.

Yong Liu [7] in his research paper analyzed the relationship between vague sets and fuzzy sets and proposed a general model to transform vague sets into fuzzy sets. A many-to-one mapping is formed in transforming a vague set to a fuzzy set. We can use this model in vague information processing systems to transform a vague information system into fuzzy information systems.

\section{BACKGROUND ON FUZZY SETS AND VAGUE SETS}

\subsection{Fuzzy Sets}

Definition: A fuzzy $\mathrm{Z}$ set is a set of ordered pairs, given by

$$
Z=\left\{\left(x, \mu_{z}(x)\right): x \in Z\right\}
$$

where $\mathrm{Z}$ is the universe of discourse, and $\mu_{Z}(x)$ is membership function of the element $\mathrm{x}$ in $\mathrm{Z}$ such that $0 \leq \mu_{z}(x) \leq 1$ [2], and $\mathrm{x}$ is a real number.

In a general language, a fuzzy set provides a framework to deal with situations where a sharply defined criteria is absent in defining the sets of elements. A membership function is an inherent part of this framework. It maps an element to a positive real number in the interval $[0,1]$. The function of the 
membership functions is to implement fuzzification using different shapes and formulas.

\subsection{Vague Sets}

Definition: A vague set is generalization of a fuzzy set. A vague set in $\mathrm{V}$ in $\mathrm{X}$ is characterized by two membership functions, namely a truth-membership function $t_{v}(i)$ and a false-membership function $f_{v}(i)$, where $t_{v}(i)$ is lower bound of the grade of membership of $i$ derived from the "evidence for $i$, and $f_{v}(i)$ is a lower bound of the negation of grade of membership of $i$ derived from the 'evidence against $i$ '.

$1-f_{w}(i)$

$t_{v}(i)$

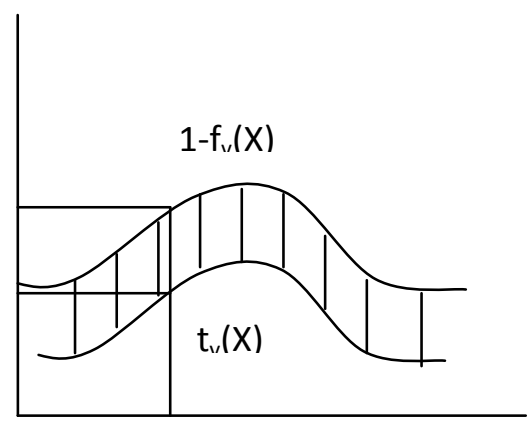

Fig 1: Illustration of a Vague Set.

The uncertainty in a vague set is represented by the difference $1-f_{v}(i)-t_{v}(i)$. If this value is small, our knowledge is relatively precise and if the value is large our knowledge is little. A vague set represents the grade of membership $\mu_{v}(i)$ bounded by $t_{v}(i) \leq \mu_{v}(i) \leq 1-f_{v}(i)$, where $t_{v}(i)+f_{v}(i) \leq 1$. A vague set tends to be equal to a fuzzy set if $t_{v}(i)=1-f_{v}(i)$. The vague set theory reverts back to ordinary set theory if both $t_{v}(i)$ and $1-f_{v}(i)$ are equal to 1 or 0 [3]. The vague set concept is shown graphically in figure 1.

The above concept can be interpreted with an example, consider a vague set $\mathrm{X}\left[\mathrm{t}_{\mathrm{A}}(\mathrm{x}), 1-\mathrm{f}_{\mathrm{A}}(\mathrm{x})\right]=[.5, .3]$. This set indicates that the degree of $\mathrm{x}$ belonging to $\mathrm{A}$ is .5 , degree of $\mathrm{x}$ not belonging to $\mathrm{A}$ is .3 and .2 degree means that $\mathrm{x}$ is in neutral or abstained position.

\section{FUZZIFICATION TECHNIQUES}

The process of transforming a crisp value to a fuzzified grade of membership is known as fuzzification. In this process we recognise that many quantities that we consider crisp and deterministic are not deterministic, they are contained with uncertainty. By identifying these uncertainties present in crisp values we form the fuzzy values [8]. As a result of this uncertainty fuzzification is performed.

A variable is fuzzy and is represented by a membership function if its uncertainty arises as a result of imprecision and vagueness. The membership function formation includes graphical representations in form of different shapes and equations. As previously discussed different forms of membership functions with different graphical representation and equations are implemented and used, some of them are discussed in this section.

\subsection{Functions for Fuzzification}

The simplest membership functions are formed with straight lines. The two membership functions formed using straight lines are Triangular and Trapezoidal membership functions. The triangular membership function, named trimf, is a collection of three points forming a triangle. The graphical representation of the triangular membership function is shown in Figure 2.

$$
\mu_{t r i}(x)=\left\{\begin{array}{cc}
0 & x<l \\
1-\frac{|c-x|}{(r-l) / 2} & l<x<r \\
0 & x>r
\end{array}\right.
$$

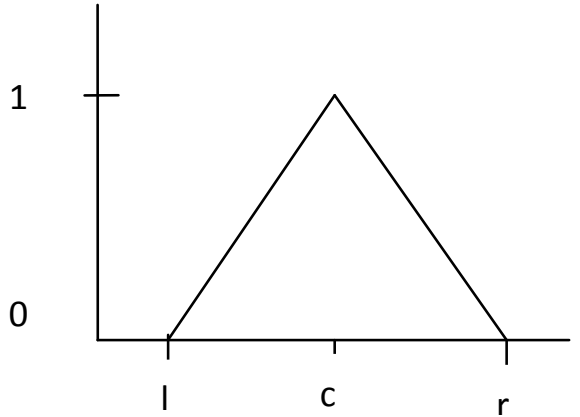

Fig 2: A Triangular Membership Function.

Where $\mathrm{c}$ is the centre, 1 and $\mathrm{r}$ are the left and right bounds, respectively, of the triangle.

The trapezoidal membership function, named trapmf, is a truncated triangle curve with flat top. The graphical representation of the trapezoidal membership function is shown in Figure 3.

$$
\mu_{\text {trap }}(x)=\left\{\begin{array}{cc}
0 & x<\text { lor } x>r \\
\frac{|x-l|}{\left(c-\frac{w}{2}-l\right)} & l<x<c-\frac{w}{2} \\
1 & c-\frac{w}{2}<x<c+\frac{w}{2} \\
\frac{(r-x)}{r-(c+w / 2)} & c+\frac{w}{2}<x<r
\end{array}\right.
$$

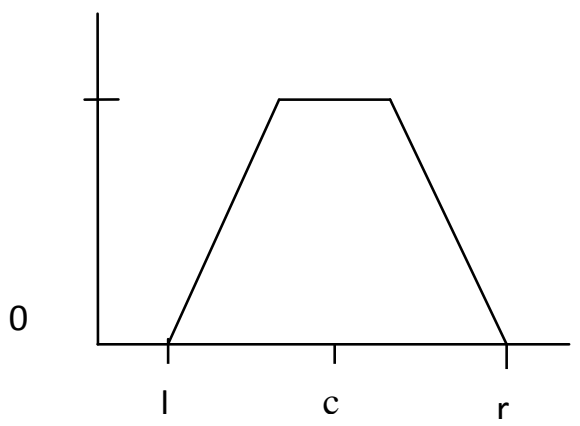

Fig 3: A Trapezoidal Membership Function.

Where $\mathrm{c}$ is the centre, 1 and $\mathrm{r}$ are the left and right bounds, respectively, and $\mathrm{w}$ is the width of the top side of trapezoid.

The Gaussian Distribution Curve is implemented to generalize two membership functions, named gaussmf and gauss $2 \mathrm{mf}$ [9]. The Gaussian membership function is shown graphically in figure 4 . The function for these membership functions is:

$$
\mu(x)=\exp \left(-\frac{(x-c)^{2}}{2 \sigma^{2}}\right)
$$




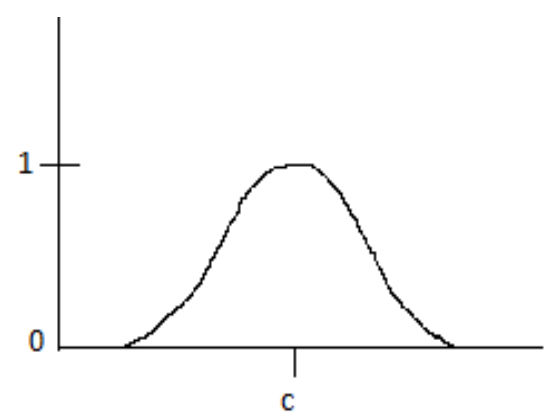

Fig 4: A Gaussian Membership Function

Where $\mathrm{c}$ is centre of curve and $\sigma$ is width of membership function or standard deviation.

\section{VAGUE-FUZZIFICATION}

In this section we introduce a new technique to implement fuzzification by combining two different techniques [6] [7]. Vague-Fuzzification technique works in two steps as shown in figure 5. In first we have used POTF; Positive Ordered Transforming Formula to transform crisp data into vague data with truth membership value and false membership value. In second step this vague data is converted into fuzzy data.

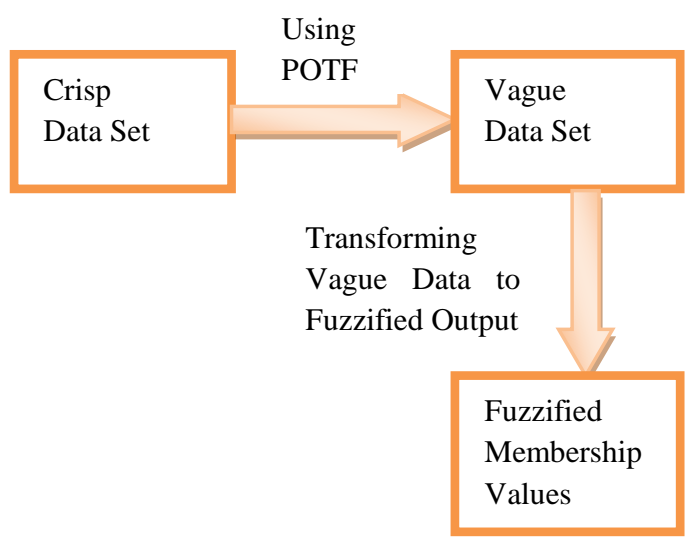

Fig. 5: Vague-Fuzzification technique.

Positive Ordered Transforming Formula: POTF Transform a non-negative single value data into a vague value data [6]. Given an index set of single-value data, this formula computes truth membership value and negation of false membership value of each single value data one by one taken from the index set.

$\mathrm{V}_{\mathrm{i}}\left(\mathrm{c}_{\mathrm{j}}=\left[\mathrm{t}_{\mathrm{ij}}, 1-\mathrm{f}_{\mathrm{ij}}\right]\right)=\left[\frac{c_{i j}^{p}-c_{j \min }^{p}}{c_{j \max }^{p}-c_{j \min }^{p}}, 1-\frac{c_{j \max }-c_{i j}}{c_{j \max }-c_{j \min }}\right]$

Where $c_{i j}$ is single-value to be transformed, $c_{j m i n}$ is minimum value from the index set, $c_{\text {jmax }}$ is max value of the index set, and $p=2,3,4 \ldots$.

Transforming Formula from Vague Sets to Fuzzy Sets: A general model is designed to transform a given vague set, with truth membership value and false membership value, into its equivalent fuzzy set with better understanding of uncertainty [7]. Given an element $u \in \mathrm{U}$, with its vague value $\left[\mathrm{t}_{\mathrm{i}}(\mathrm{u}), 1-\right.$ $f_{i}(u)$. This transforming formula defines the fuzzy membership function of the vague set $u$.

$\mu_{\mathrm{i}}=\mathrm{t}_{\mathrm{i}}(\mathrm{u})+\left(\frac{1}{2}\left[1+\frac{t_{i}(u)-f_{i}(u)}{t_{i}(u)+f_{i}(u)+2 \alpha}\right]\left[1-t_{i}(u)-f_{i}(u)\right]\right)$.

Where $\mathrm{t}_{\mathrm{i}}(\mathrm{u})$ is truth membership value of $u, \mathrm{f}_{\mathrm{i}}(\mathrm{u})$ is false membership value of $u$, and $\alpha$ is a positive real number.
The technique is illustrated step-by-step below.

\subsection{Technique: Vague-Fuzzification}

Input: Crisp value, $\mathrm{c}_{\mathrm{ij}}$.

Output: Fuzzyfied value, $\mu_{\mathrm{i}}$

1. Let $\mathrm{C}=\mathrm{c}_{1}, \mathrm{c}_{2}, \mathrm{c}_{3} \ldots \mathrm{c}_{\mathrm{n}}$ be an index set and index $\mathrm{c}_{j}$ $(j=1,2,3 \ldots n)$ of program $P_{i}(i=1,2,3 \ldots m)$ be a single value crisp data $\mathrm{c}_{\mathrm{ij}}$

2. Let $c_{j \min }=\min \left\{c_{1 j}, c_{2 j}, c_{3 j} \ldots c_{m j}\right\}, c_{j \max }=\max \left\{c_{1 j}\right.$, $\left.c_{2 j}, c_{3 j} \ldots c_{m j}\right\}$. Then

$\mathrm{V}_{\mathrm{i}}\left(\mathrm{c}_{\mathrm{j}}=\left[\mathrm{t}_{\mathrm{ij}}, 1-\mathrm{f}_{\mathrm{ij}}\right]\right)=\left[\frac{c_{i j}^{p}-c_{j \min }^{p}}{c_{\text {jmax }}^{p}-c_{\text {jmin }}^{p}}, 1-\frac{c_{\text {jmax }}-c_{i j}}{c_{\text {jmax }}-c_{\text {jmin }}}\right]$

where $(p=2)$.

3. Now, take the output of step three, $V_{i}\left(c_{j}=\left[t_{i j}, 1-f_{i j}\right]\right)$ and apply equation (2) given in step 4.

4. $\mu_{\mathrm{i}}=\mathrm{t}_{\mathrm{i}}(\mathrm{u})+\left(\frac{1}{2}\left[1+\frac{t_{i}(u)-f_{i}(u)}{t_{i}(u)+f_{i}(u)+2 \alpha}\right]\left[1-t_{i}(u)-\right.\right.$ $\left.\left.f_{i}(u)\right]\right)$.

where $\alpha$ is a positive real number.

5. The output of equation given in step 4 is a fuzzyfied grade of membership value of the input value $c_{\mathrm{ij}}$.

6. Apply step 2 to 5 for each next value of the input provided in index set

\section{RESULTS}

We have implemented Vague-Fuzzification technique using MATLAB on different datasets of crisp values.

\subsection{Case Study 1}

Assume a set of crisp values, $X=[45,42,61,84,10,60,50$, $62,82]$. Firstly vague values are calculated for each single value of the set using step 2 , and further fuzzified data is calculated for each vague value using step 3 . The calculated fuzzified values by Vague-Fuzzification technique are compared with fuzzified values calculated using Triangular Membership Function [10]. All the calculations are performed on MATLAB and the result is summarized in the table 1.

Table 1. Calculations and comparison

\begin{tabular}{|c|c|c|c|}
\hline $\begin{array}{c}\text { Crisp } \\
\text { Data }\end{array}$ & $\begin{array}{c}\text { Vague Set } \\
\text { Data }\end{array}$ & $\begin{array}{c}\text { Fuzzyfied } \\
\text { Data }\end{array}$ & $\begin{array}{c}\text { Fuzzy } \\
\text { Triangular } \\
\text { MF }\end{array}$ \\
\hline 45 & {$[.277, .473]$} & .3665 & .083 \\
\hline 42 & {$[.239, .433]$} & .3245 & .033 \\
\hline 61 & {$[.52, .689]$} & .6111 & .35 \\
\hline 84 & {$[1,1]$} & 1 & .733 \\
\hline 10 & {$[0,0]$} & 0 & 0 \\
\hline 60 & {$[.503, .676]$} & .595 & .33 \\
\hline 50 & {$[.345, .541]$} & .439 & .167 \\
\hline 62 & {$[.538, .702]$} & .627 & .366 \\
\hline 82 & {$[.952, .973]$} & .9658 & .7 \\
\hline
\end{tabular}




\subsection{Case Study 2}

Consider another set of crisp values, $\mathrm{A}=[90,45,72,69,184$, $120,18,38,147,105]$. The corresponding vague and fuzzified sets are computed as shown in table 2 .

Table 2. Calculations and comparison

\begin{tabular}{|c|c|c|c|}
\hline $\begin{array}{c}\text { Crisp } \\
\text { Data }\end{array}$ & $\begin{array}{c}\text { Vague Set } \\
\text { Data }\end{array}$ & $\begin{array}{c}\text { Fuzzyfied } \\
\text { Data }\end{array}$ & $\begin{array}{c}\text { Fuzzy } \\
\text { Triangular } \\
\text { MF }\end{array}$ \\
\hline 90 & {$[.232, .434]$} & .3207 & .5 \\
\hline 45 & {$[.051, .163]$} & .0914 & .05 \\
\hline 72 & {$[.145, .325]$} & .2182 & .32 \\
\hline 69 & {$[.133, .307]$} & .2024 & .29 \\
\hline 184 & {$[1,1]$} & 1 & .56 \\
\hline 120 & {$[.419, .615]$} & .5183 & .8 \\
\hline 18 & {$[0,0]$} & 0 & 0 \\
\hline 38 & {$[.034, .121]$} & .0643 & 0 \\
\hline 147 & {$[.635, .777]$} & .7162 & .93 \\
\hline 105 & {$[.319, .524]$} & .4158 & .65 \\
\hline & & & \\
\hline
\end{tabular}

\section{CONCLUSION}

A new technique is proposed and tested to implement fuzzification. The base of this technique is vague set concepts that provide a better environment to handle vagueness and uncertainty. Using two previously implemented techniques, this research paper merged them to have a different understanding of fuzzification. A step-wise procedure we designed is accompanied with results of vague sets and fuzzy sets providing a comparison among two illustrated techniques.
Two different cases are studied here with different data sets. This technique developed can be used in a fuzzy inference system in the fuzzification module. Presently we are working on such a system that uses this technique we provide here which will surely provide different and better results.

\section{REFERENCES}

[1] Zadeh, L., A. 1965 Fuzzy Sets, Information and control $8,338-353$.

[2] Konar, Amit 2005 Fuzzy Sets and Relations, Computational Intelligence, Principles, Techniques and Applications, 37- 66.

[3] Gau, Wen-Lung, J., Buehrer, Daniel 1993 Vague Sets, IEEE Transactions on Systems, Man and Cybernetics, Vol. 23, No. 2, March/April 1993.

[4] Kumar, Amit, Prasad Yadav, Shiv, and Kumar, Surendra Fuzzy System Reliability Using Different Types of Vague Sets, Journal of Applied Sciences and Engineering, Vol. 6, No. 1, 71-83.

[5] M., Passino, Kevin, Yurkovich, Stephen 1998 Fuzzy Control, Addison Wesley, 56- 57.

[6] Guxin, Li, Hong-xu, Wang, and Chengyi, Zhang 2010 Constructing Vague Environment, Fuzzy Information and Engineering, AICS 78, 711-715.

[7] Liu, Yong, Wang, Guoyin, and Feng, Lin 2008 A General Model for Transforming Vague Sets into Fuzzy Sets, Transactions on Computer Science II, LNCS 5150, 133-144.

[8] Sivanandam, S., N., Sumathi, S., and Deepa, S., N. 2007 Introduction to Fuzzy Logic Using MATLAB, Springer, 76.

[9] Fuzzy Logic ToolBox, User's Guide, Vol. 2, The MathWorks, 1995-2000.

[10] Hooda, Priya, Raheja, Supriya 2014 A New Approach to Disk Scheduling Using Fuzzy Logic, Journal of Computer and Computation, Vol. 2, 1-5, January 2014. 